\title{
Kinetics and Mechanism of $\beta$-Brass Dealloying in Aqueous 0.5 M Sodium Chloride Solution Derived from Combined Scanning Tunneling Microscopy and Electrochemical Data
}

\author{
J. Morales, P. Esparza, and S. Gonzalez \\ Departamento de Química Física, Universidad de La Laguna, Tenerife, Spain \\ L. Vazquez \\ Instituto de Ciencia de Materiales, CSIC, Departamento de Fisica Aplicada, \\ C-XII, Universidad Autónoma de Madrid (UAM), 28049 Madrid, Spain \\ R. C. Salvarezza and A. J. Arvia* \\ Instituto de Investigaciones Fisicoquímicas Teóricas y Aplicadas (INIFTA), \\ Sucursal 4, Casilla de Correo 16, 1900 La Plata, Argentina
}

Received May 26, 1995. In Final Form: September 18, $1995^{\otimes}$

\begin{abstract}
Scanning tunneling microscopy (STM) combined with conventional electrochemical techniques was used to determine the kinetics and mechanism of $\beta$-brass dealloying in aqueous neutral solutions containing $\mathrm{NaCl}$. In the potential range where selective dissolution of $\mathrm{Zn}$ occurs, electrochemical data suggest that the corrosion process is controlled by surface diffusion of $\mathrm{Cu}$ atoms. STM imaging of $\beta$-brass after dealloying shows the development of an irregular surface which attains a stationary regime. The irregular surface topography consists of faceted islands with atomically smooth terraces. For a constant dealloying time, the extent of faceting increases as the potential is moved positively, and at a constant applied potential it increases with electrodissolution time. The proportionality $\xi \propto L^{\alpha}$ was established, where $\xi$ is the interface width related to $L$, the sample size. The exponent $\alpha$ is related to the degree of surface disorder. The value of $\alpha$ derived from STM is in the range $0.7 \leq \alpha \leq 0.8$, i.e. close to the predictions of aggregation models including surface diffusion.
\end{abstract}

\section{Introduction}

The stability of binary alloys in aqueous environments ${ }^{1-4}$ depends on the alloy composition at the surface, ${ }^{5}$ the solution composition, ${ }^{6}$ the surface alloy pretreatment, and temperature. ${ }^{7,8}$

Dealloying appears as a complex process related to different problems such as metallic corrosion, including stress corrosion cracking, and heterogeneus catalysis. The loss of the alloy properties often occurs by dealloying, i.e., the selective dissolution of the less noble metal. In general, polarization curves for binary alloys in an agressive aqueous environment exhibit a region of very low potentialindependent current (region a) followed by another region of a rapidly increasing current (region b). The potential transition between regions a and b takes place at $E_{\mathrm{c}}$, the critical potential of the alloy. Below $E_{\mathrm{c}}$, the electrodissolution of the most active species results in a protective metal layer of the most noble constituent which in turn, under favorable conditions, hinders the corrosion process. At this stage no remarkable changes in the corroding surface roughness can be observed. Conversely, above

\footnotetext{
${ }^{\otimes}$ Abstract published in Advance ACS Abstracts, November 15 1995.

(1) Kaiser, H. Corrosion Mechanisms; Mansfeld, F., Ed.; Marcel Dekker: New York, 1987; Chapter 23, p 85.

(2) Newman, R. C.; Shahrabi, T.; Sieradzki, K. Corros. Sci. 1988, 28, 873 .

(3) Scully, J. C. Met. Sci. 1978, 12, 290 and references therein.

(4) Hardie, D.; Ebtehaj, K. Br. Corros. J. 1987, 22, 202.

(5) Pickering, H. W. Corros. Sci. 1983, 23, 1107.

(6) Moffat, T. P.; Fan, R. F.; Bard, A. J. Electrochem. Soc. 1991, 138, 3224 .

(7) Trethewey, K.; Chamberlain, J. Corrosion; Longman: Essex, 1988, and references therein.

(8) Askeland, D. R. The Science and Engineering of Materials; PWSKent Publishing Company: Boston, MA, 1989.
}

$E_{\mathrm{c}}$, the protective layer breaks, leading to massive dealloying and profuse surface roughening.

For $\mathrm{Zn}-\mathrm{Cu}$ alloys (brass) immersed in aqueous $\mathrm{NaCl}$ solution, the transition from region a to region $\mathrm{b}$ cannot be determined because $\mathrm{Cu}$ begins to dissolve below $E_{\mathrm{c}}{ }^{2}$ However, the selective dissolution in region a is easily achieved provided that $E$, the applied potential, is lower than the potential associated with the onset of $\mathrm{Cu}$ electrodissolution.

Several mechanisms have been proposed to explain dealloying. One of them, known as the divacancy mechanism, ${ }^{9}$ considers that the electrodissolution rate of the less noble element is controlled by its solid state diffusion via divacancy formation. ${ }^{10}$ Accordingly, the interface develops irregularities growing with time. Another mechanism for dealloying ${ }^{11}$ considers that the surface diffusion of the most noble metal atoms is rate determining, leading to aggregates of the most noble element which finally produce an island-channel microstructure.

On the other hand, recent STM imaging on Au-rich Ag$\mathrm{Au}$ alloy surfaces has shown that the electrodissolution proceeds from terraces forming cluster vacancies. ${ }^{12}$ STM images taken during $\mathrm{Cu}$ electrodissolution from polycrystalline $\mathrm{Cu}_{3} \mathrm{Au}^{13}$ reveal the formation of two- (2D) and three-dimensional (3D) nuclei. In any case, independent of the mechanistic interpretation of dealloying, it is clear that this process is accompanied by a progressive rough-

(9) Pickering, H. W.; Wagner, C. J. Electrochem. Soc. 1967, 114, 698. (10) Fritz, J. D.; Pickering, H. W. J. Electrochem. Soc. 1991, 138 3209.

(11) Tischer, R. P.; Gerischer, H. Z. Electrochem. 1958, 62, 50. Forty, A. J.; Durkin, P. Philos. Mag. 1985, 42, 295. Sieradzki, K.; Corderman, R. R.; Shukla, K.; Newman, R. C. Philos. Mag. 1989, 59, 713.

(12) Oppenheim, I. C.; Trevor, D. J.; Chidsey, C. E. D.; Trevor, P. L.; Sieradzki, K. Science 1991, 254, 687.

(13) Burstein, G. T.; Gao, G. J. Electrochem. Soc. 1994, 141, 912. 
ening of the dissolving interface. ${ }^{14}$ However, despite the relevance of roughness development during dealloying, no quantitative data on the roughness characteristics of these systems have been reported so far.

In this paper the electrochemical behavior of $\beta$-brass is studied using potentiostatic and potentiodynamic techniques combined with "ex-situ" STM imaging. The roughness properties of $\beta$-brass, after dealloying at different potentials in region a, are interpreted by the dynamic scaling theory ${ }^{15}$ applied to STM images. Results show that under different experimental conditions the value of $\alpha$, the characteristic roughness exponent of the corroding specimen, is close to the predictions of aggregation models incorporating surface diffusion.

\section{Experimental Section}

Working electrodes (specimens) were made from $\beta$-brass bars, with the following chemical composition: $52.46 \% \mathrm{Cu}, 47.49 \%$ $\mathrm{Zn}, 0.026 \%$ C, $0.005 \% \mathrm{Al}, 0.023 \% \mathrm{Sn}$, As and $\mathrm{Si}<0.001$. Brass bars were made from known amounts of $99.999 \% \mathrm{Cu}$ and $99.999 \%$ Zn by casting and melting. Drawn brass bars $0.6 \mathrm{~cm}$ in diameter were machined to obtain cylindrical specimens $0.3 \mathrm{~cm}$ in diameter. The base of the brass cylinder was used as a horizontal disk working electrode in contact with a hanging electrolyte solution column. ${ }^{16}$ The working electrode (specimen) was wet-polished using different grain size emery papers, and finishing was made with $1 \mu \mathrm{m}$ grit alumina paste. Then each specimen was successively rinsed with distilled acetone in an ultrasonic bath and with twice distilled water and, finally, dried in air at room temperature. Finally, specimens were lodged under low $\mathrm{Ar}$ pressure in a Pyrex tubing to be treated at $150{ }^{\circ} \mathrm{C}$ for $2 \mathrm{~h}$ to eliminate residual mechanical stresses and to improve their surface homogeneity. This pretreatment assured the reproducibility of results. After etching pretreated specimens in acid $\mathrm{Fe}_{3} \mathrm{Cl}$, a grain size density close to 50 grains $\mathrm{cm}^{-2}$ was found, i.e., the alloy was formed by large grains so that a $1 \times 1 \mu \mathrm{m}^{2}$ STM imaging was adequate to characterize a single grain surface. The $1 \times 1 \mu \mathrm{m}^{2}$ STM image (Figure 1a) of the noncorroded specimen shows a relatively smooth topography (Figure $1 \mathrm{~b}$ ) with a root mean square roughness $\left(\xi_{\mathrm{stm}}\right)$ value close to $1.9 \mathrm{~nm} .{ }^{17}$

Electrochemical runs were made using a conventional threeelectrode Pyrex glass cell containing aqueous $0.5 \mathrm{M} \mathrm{NaCl} \mathrm{pH} 7$, at $25^{\circ} \mathrm{C}$, saturated with Ar. The potential of each specimen was measured against a saturated calomel electrode (SCE) provided with a conventional Luggin-Haber capillary tip arrangement. A large platinum wire was used as counterelectrode. All electrochemical runs were made at $25^{\circ} \mathrm{C}$.

Anodic polarization curves were run from $-1.3 \mathrm{~V}$ in the positive potential direction at the scan rate $V=2 \times 10^{-3} \mathrm{~V} \mathrm{~s}^{-1}$. Voltammograms were also recorded in the range $0.05 \mathrm{~V} \mathrm{~s}^{-1}<V$ $<0.2 \mathrm{~V} \mathrm{~s}^{-1}$. Potentiostatic current transients were made by stepping $E$, the applied potential, from $E=-1.3 \mathrm{~V}$ to an $E_{\mathrm{s}}$ value in the range $-0.65 \mathrm{~V}<E_{\mathrm{s}}<-0.45 \mathrm{~V}$. Occasionally, the rotation speed of the working electrode was varied in the range $0 \leq \omega \leq$ $3000 \mathrm{rpm}$. In all cases the current density $(j)$ was referred to the geometric area of the working electrode. During each run $\beta$-brass specimens were removed from the cell at a definite time $(t)$, rinsed with twice-distilled Ar saturated water, dried under $\mathrm{N}_{2}$, and finally kept under vacuum until proceeding to the ex-situ STM observation which typically takes no more than $4 \mathrm{~h}$. The STM imaging was made using a Nanoscope III (Digital Instruments, Santa Barbara CA), Pt-Ir Nanotips, a bias voltage in the range 0.1 to $-2.5 \mathrm{~V}$ at $1-5 \mathrm{nA}$ constant current. To discard occasional imaging artifacts due to tip geometry, different tips were used, although no influence of the tip shape on our experimental data was detected. In order to minimize errors, ${ }^{18}$ STM images with

(14) Sieradzki, K. J. Electrochem. Soc. 1993, 140, 2868 and references therein.

(15) Family, F. Physica A 1990, 168, 561 and references therein.

(16) Elsner, C. I.; Schilardi, P.; Marchiano, S. L. J. Appl. Electrochem. 1993, 23,1181 .

(17) Shreir, L. L.; Jarman, R. A.; Burstein, G. T. Corrosion; Butterworth-Heineman Ltd: Oxford, 1994.

(18) Vázquez, L.; Salvarezza, R. C.; Herrasti, P.; Ocón, P.; Vara, J. M.; Arvia, A. J. Appl. Surf. Sci. 1993, 70, 413.

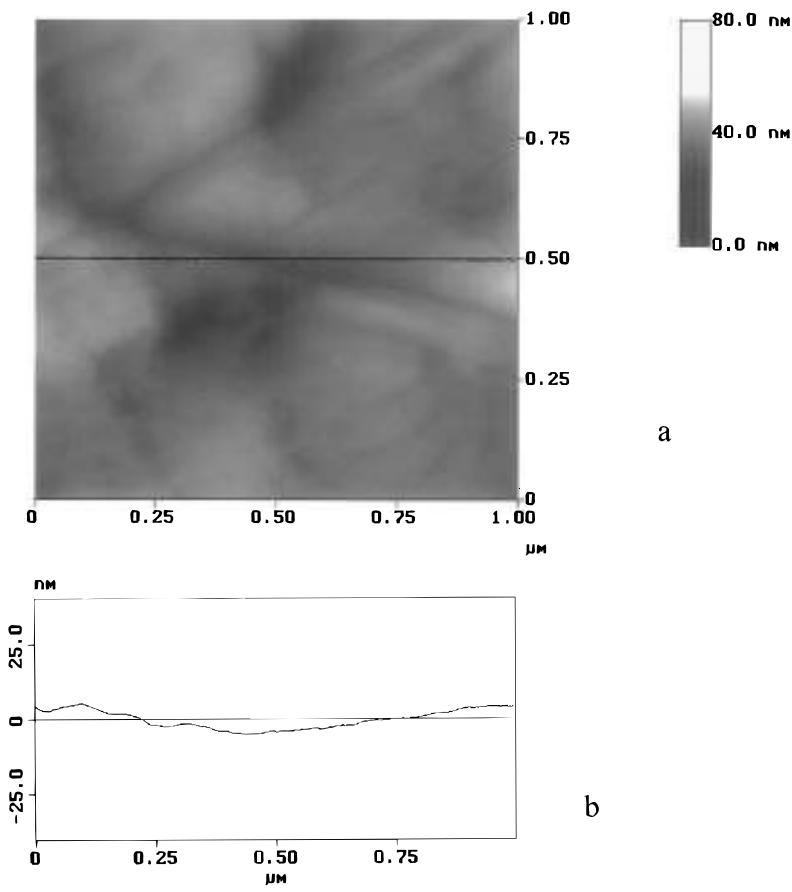

Figure 1. (a) A $1 \times 1 \mu \mathrm{m}^{2}$ STM image of a noncorroded $\beta$-brass specimen $\left(\xi_{\mathrm{stm}}=1.9 \mathrm{~nm}\right)$. (b) The cross section corresponds to the line marked in Figure 1a. A grain boundary is shown in the image.

$512 \times 512$ pixels were taken. STM data were analyzed after fitting and removing the plane of the substrate. ${ }^{19}$

\section{Results}

3.1. Polarization Curves. Anodic apparent current density $(j)$ vs potential $(E)$ curves were recorded between -1.2 and $-0.30 \mathrm{~V}$ at $v=2 \times 10^{-3} \mathrm{~V} \mathrm{~s}^{-1}$ in aqueous $\mathrm{NaCl}$ containing solution (Figure 2a). These curves exhibit a cathodic current contribution related to the hydrogen evolution reaction (HER), followed by the broad anodic current peak $\mathrm{A}(\mathrm{I})$ at $-0.80 \mathrm{~V}$, a current plateau extending between -0.70 and $-0.35 \mathrm{~V}$ and the small anodic peak $\mathrm{A}$ (II) in the range $-0.48<E<-0.40 \mathrm{~V}$ which largely overlaps the current plateau. Finally, for $E>-0.4 \mathrm{~V}$, a considerable increase in the anodic current (A(III)) was produced.

Both $\mathrm{A}(\mathrm{I})$ and $\mathrm{A}(\mathrm{II})$ and the anodic current plateau remained insensitive to the electrode rotation $(\omega)$ in the range $0<\omega<2000 \mathrm{rpm}$.

3.2. Voltammetric Data. Voltammograms (first scan) run in aqueous $\mathrm{NaCl}$-containing solution between -1.5 and $-0.25 \mathrm{~V}$ at $v=0.02 \mathrm{~V} \mathrm{~s}^{-1}$ (Figure 2b) show that peak $\mathrm{A}(\mathrm{I})$ consists of two anodic peaks, namely peak $\mathrm{A}(\mathrm{I})^{\prime}$ at $-1.2 \mathrm{~V}$ and peak $\mathrm{A}(\mathrm{I})^{\prime \prime}$ at $-0.75 \mathrm{~V}$. A slight increase in current related to peak A(II) is also observed at $-0.5 \mathrm{~V}$. The reverse scan shows peaks C(II) at $-0.5 \mathrm{~V}, \mathrm{C}(\mathrm{I})^{\prime \prime}$ at $-1.0 \mathrm{~V}$, and $\mathrm{C}(\mathrm{I})^{\prime}$ at $-1.2 \mathrm{~V}$ which are the conjugated peaks of $\mathrm{A}(\mathrm{II}), \mathrm{A}(\mathrm{I})^{\prime}$, and $\mathrm{A}(\mathrm{I})$, respectively, as concluded from those experiments in which the anodic and cathodic switching potentials were systematically changed. Likewise, the pairs of peaks A(II)/C(II) and A(III)/C(III) are clearly resolved when the cathodic switching potential is increased from -1.5 to $-1.3 \mathrm{~V}$ (Figure 2c). Continuous cycling of the the brass electrodes produces a gradual change in the height of current peaks due to the increase in the surface area caused by the selective dissolution and accumulation of corrosion products. For this reason

(19) Krim, J.; Hevaert, I.; Haesendock, C.; Bruynseraede, Y. Phys. Rev. Lett. 1993, 70, 57. 

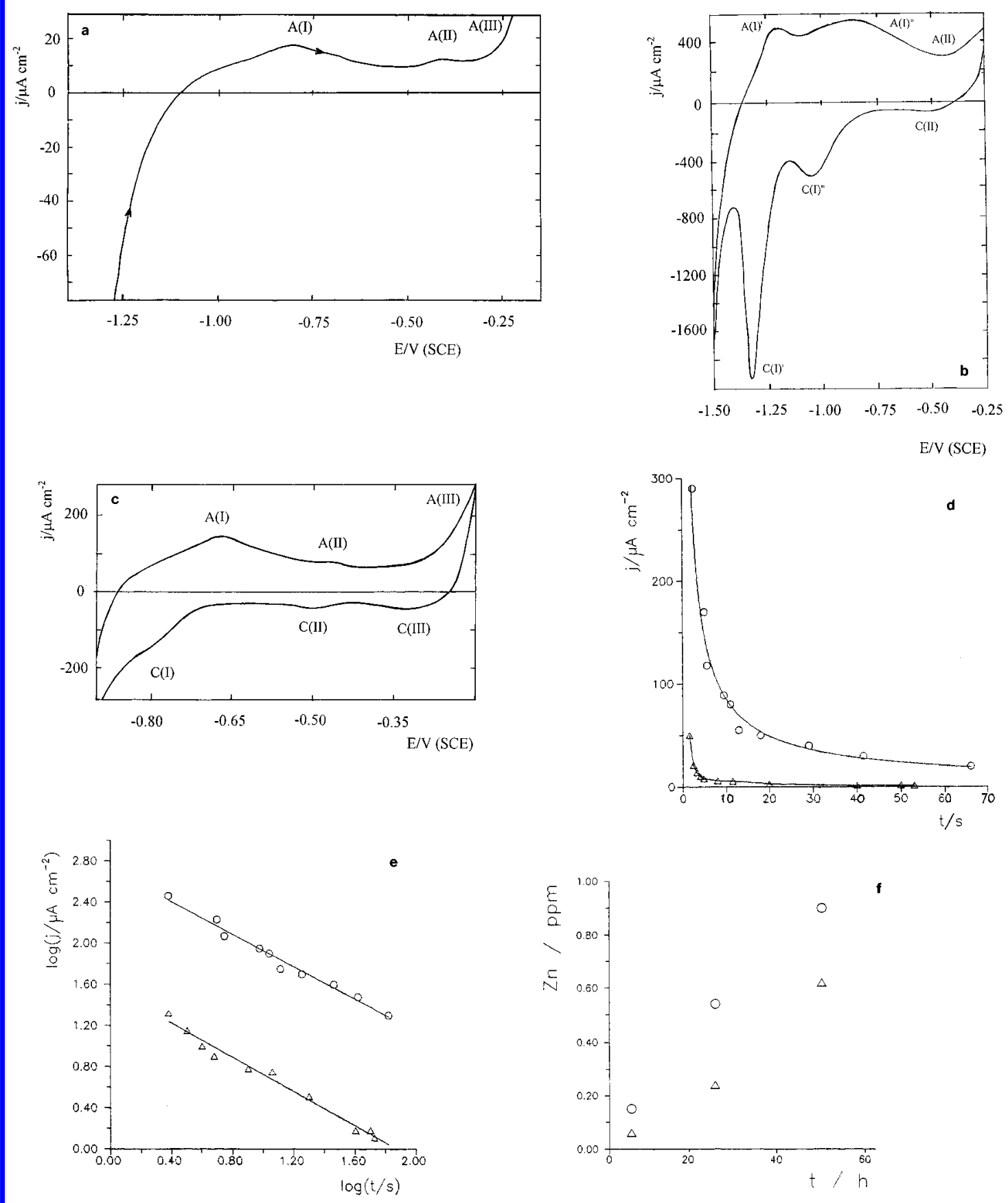

Figure 2. Electrochemical data resulting from $\beta$-brass immersed in aqueous $0.5 \mathrm{M} \mathrm{NaCl}, \mathrm{pH} 7.0,25{ }^{\circ} \mathrm{C}, \omega=0 \mathrm{rpm}$ : (a) anodic $j$ vs $E$ profile run between -1.3 and $-0.3 \mathrm{~V}$ at $V=2 \times 10^{-3} \mathrm{~V} \mathrm{~s}^{-1}$; (b) voltammogram run between -1.5 and $-0.25 \mathrm{~V}$ at $V=0.02$ $\mathrm{V} \mathrm{s}^{-1}$; (c) voltammogram run between -1.3 and $-0.25 \mathrm{~V}$ at $v=0.02 \mathrm{~V} \mathrm{~s}^{-1}$, only the voltammogram from $E=-0.96 \mathrm{~V}$ upward is shown; (d) anodic current decay at $E_{\mathrm{s}}=-0.45 \mathrm{~V}(\mathrm{O})$ and $E_{\mathrm{s}}=-0.65 \mathrm{~V}(\triangle)$; (e) $\log j \mathrm{vs} \log t$ plots for anodic current transients shown in part d for $E_{\mathrm{s}}=-0.45 \mathrm{~V}(\mathrm{O})$ and $E_{\mathrm{s}}=-0.65 \mathrm{~V}(\triangle)$; (f) amount of dissolved Zn (in ppm) vs $t$ plots at $E_{\mathrm{s}}=-0.625 \mathrm{~V}(\triangle)$ and $E_{\mathrm{s}}$ $=-0.45 \mathrm{~V}(\mathrm{O})$.

only data from the first and second voltammetric scans were considered.

3.3. Potentiostatic Current Transients. The $j$ vs $t$ plots (Figure 2d) in aqueous NaCl-containing solution were recorded by stepping the potential from $E=-1.3 \mathrm{~V}$ to an $E_{\mathrm{s}}$ value in the range $-0.65 \mathrm{~V}<E_{\mathrm{s}}<-0.45 \mathrm{~V}$, which corresponds to the anodic current plateau in the polarization curves. These current transients fit a $j$ vs $t^{-0.75}$ relationship for $0 \mathrm{~s} \leq t \leq 100 \mathrm{~s}$ (Figure 2e), in agreement with previously reported data on brass dealloying. ${ }^{13}$ For $t>200 \mathrm{~s}$ a stationary anodic current density close to 3.0 $\pm 0.5 \mu \mathrm{Acm}^{-2}$ is attained. This constant current increases slightly with $E_{\mathrm{s}}$, and it is independent of $\omega$ in the range $0<\omega<2000 \mathrm{rpm}$.
3.4. Dissolution Products. The amount of $\mathrm{Zn}$ detected by atomic absorption spectroscopy in the aqueous $\mathrm{NaCl}$-containing solution depends on $E_{\mathrm{s}}$ and $t$ (Figure 2f). At a constant $E_{\mathrm{s}}$, the $\mathrm{Zn}$ content in the solution increases linearly with $t$, whereas at a constant $t$, it increases as $E_{\mathrm{s}}$ is shifted from -0.625 to $-0.45 \mathrm{~V}$. In this potential range no soluble $\mathrm{Cu}$ can be detected by atomic absorption spectroscopy, in agreement with rotating ring-disk electrode data on $\mathrm{Cu}$ electrodissolution in aqueous $0.3 \mathrm{M}$ $\mathrm{NaCl}^{20}$ Only when $E_{\mathrm{s}}>-0.40 \mathrm{~V}$ can the formation of soluble $\mathrm{Cu}(\mathrm{I})$ species be detected, i.e. when $E_{\mathrm{s}}$ lies in the

(20) Elsner, C.; Salvarezza, R. C.; Arvia, A. J. Electrochim. Acta 1988 , 33, 1735. 
potential range of peaks $\mathrm{A}(\mathrm{III}) / \mathrm{C}(\mathrm{III})$. Therefore, the anodic current plateau in the polarization curve definitely corresponds to the selective dissolution of $\mathrm{Zn}$ from the alloy with no $\mathrm{Cu}$ corrosion.

The amount of soluble $\mathrm{Zn}$ after $24 \mathrm{~h}$ correlates closely with the anodic charge involved in the potentiostatic current transients for the same period of time.

3.5. STM Imaging. The STM images of a $\beta$-brass grain kept for $24 \mathrm{~h}$ at $E_{\mathrm{s}}=-0.625 \mathrm{~V}$ (Figure 3a) differ markedly from the image of the untreated specimen (Figure 1). In fact, the STM image shown in Figure 3a corresponds to $\mathrm{a} \beta$-brass specimen after a charge equivalent to the removal of 300 monolayers of pure $\mathrm{Zn}$ has been passed. This figure corresponds roughly to 600 monolayers of $\beta$-brass alloy. STM images (Figure 3a) of electrochemically treated specimens show islands following well-defined directions which intercept forming predominantly $30^{\circ}, 60^{\circ}$, and $120^{\circ}$ angles. A cross section of this topography (Figure $3 \mathrm{~b}$ ) shows islands $100-200 \mathrm{~nm}$ in average size and an island corrugation in the range $10-15 \mathrm{~nm}$. The slope mode of the STM image at a high resolution reveals sawtooth steps (Figure 3c). At a higher magnification (Figure 3d-e), each island surface topography consists of an array of voids and clusters $10 \times 20 \mathrm{~nm}^{2}$ in average size. The surface of clusters is smooth as its corrugation is in the range $0.4-$ $1.0 \mathrm{~nm}$. Voids $0.5-3 \mathrm{~nm}$ in depth are presumably formed by aggregation of vacancies resulting from dealloying. ${ }^{21}$ Otherwise, after a $48 \mathrm{~h}$ polarization at $E=-0.625 \mathrm{~V}$ the island structure smears out, and then $3 \mathrm{D}$ clusters and facets tend to dominate the entire topography (Figure 3f,g).

On the other hand, the STM image of a $\beta$-brass specimen held at $E_{\mathrm{s}}=-0.45 \mathrm{~V}$ for $24 \mathrm{~h}$, i.e., at a potential at which $\mathrm{Cl}^{-}$-ion electroadsorption takes place (peak A(II)), shows again the aforementioned island-void structure, but the surface at islands is fully faceted (Figure $4 \mathrm{a}$ ). The cross section (Figure $4 \mathrm{~b}$ ) derived from this image exhibits islands $200 \mathrm{~nm}$ or thereabouts in size, and a 7-10-nm surface corrugation. Each island comprises a number of regular facets aligned in a well-defined direction (Figure 4c). STM images at a higher magnification reveal terraces and sawtooth steps (Figure 4d). The cross section (Figure 4e) shows that terraces are atomically smooth and that some steps are monoatomic in height. Those domains $10 \mathrm{~nm}^{2}$ in size (Figure 4f) forming smooth terraces probably result from the coalescence and relaxation of clusters similar to those depicted in Figure 3d,e. Therefore, the presence of atomically smooth terraces resulting from dealloying at $E_{\mathrm{s}}=-0.45 \mathrm{~V}$ may involve a faster vacancy aggregation than that at $E_{\mathrm{s}}=-0.65 \mathrm{~V}$. This conclusion, is consistent with the enhanced $\mathrm{Cu}$ surface atom mobility caused by $\mathrm{Cl}^{-}$-ion electroadsorption at $E_{\mathrm{s}}=-0.45 \mathrm{~V} .^{22}$ Similar surface patterns can be observed for $\beta$-brass specimens held at $E_{\mathrm{s}}=-0.45 \mathrm{~V}$ for $t=50 \mathrm{~h}$.

It should be noted that in the analysis of the STM images of $\beta$-brass, image quality is improved by using a tip-sample voltage in the range -0.5 to $-1.0 \mathrm{~V}$, a working condition which points out the likely presence of a thin $\mathrm{ZnO}$ or $\mathrm{CuCl}$ coating formed in region a. Hence, the atomic corrugation observed at smooth surfaces yielding the interatomic distance $d \cong 0.4 \mathrm{~nm}$, and a corrugation close to $0.2 \mathrm{~nm}$ in height (Figure $4 \mathrm{f}$ ), could be assigned to either $\mathrm{a} \mathrm{ZnO}$ or $\mathrm{CuCl}$ thin layer on the specimen. In fact, recent STM data reported for $\mathrm{Cu}$ electrodissolution in aqueous $\mathrm{NaCl}$ solution have yielded similar values of $d$ which has been assigned to a $\mathrm{CuCl}$ layer. ${ }^{22}$

(21) Chen, S. J.; Sanz, F.; Ogletree, D. F.; Hallmark, V. M.; Devine, T. M.; Salmeron, M. Progress in the Understanding and Prevention of Corrosion; Costa, J. M., Mercer, A. D., Eds.; The Institute of Materials: London, 1993; p 1664.

(22) Suggs, D. W.; Bard, A. J. J. Am. Chem. Soc. 1994, 116, 10725.
For $1 \times 1 \mu \mathrm{m}^{2}$ STM images of $\beta$-brass held at $E_{\mathrm{s}}=-0.45$ $\mathrm{V}$ in the aqueous $\mathrm{NaCl}$-containing solution, the root mean square roughness $\left(\xi_{\text {stm }}\right)$ seems to increase with electrodissolution time until a constant $\xi_{\text {stm }}$ value for $t>20 \mathrm{~h}$ is attained (Figure 5). On the other hand, $\xi_{\text {stm }}$ values resulting from STM images of specimens held at $E_{\mathrm{s}}=$ $-0.625 \mathrm{~V}$ are smaller than those obtained for $E_{\mathrm{s}}=-0.45$ $\mathrm{V}$ in the same solution, although a constant value is also attained. This difference in values of $\xi_{\text {stm }}$ is consistent with an increasing dealloying as $E_{\mathrm{s}}$ is shifted positively (Figure 2f). Therefore, from the analysis of data shown in Figures $2 \mathrm{f}$ and 5 , it can be concluded that for a constant rate of dealloying a steady-state regime for the width of the reacting interface is reached. This means that the value of the root mean square roughness remains unchanged with dealloying time.

\section{Discussion}

4.1. Processes Involved in $\beta$-Brass Electrodissolution in Aqueous NaCl Containing Solution. The electrochemical dissolution of $\beta$-brass in an aqueous solution containing $\mathrm{NaCl}$ involves a number of conjugated processes occurring at well-defined potential regions. Anodic peaks $\mathrm{A}(\mathrm{I})^{\prime}$ and $\mathrm{A}(\mathrm{I})^{\prime \prime}$ are related to the electroformation of a $\mathrm{ZnO} \cdot \mathrm{xH}_{2} \mathrm{O}$ layer, and $\mathrm{Zn}$ electrodissolution leading to a depletion of $\mathrm{Zn}$ atoms at the alloy surface and the formation of a $\mathrm{Cu}$-rich layer. ${ }^{2,13}$ As the conjugated cathodic peaks $\mathrm{C}(\mathrm{I})^{\prime}$ and C(II)" involve only a $1.2 \mathrm{mC} \mathrm{cm}^{-2}$ apparent charge density, the thickness of the $\mathrm{ZnO}$ layer should not exceed two to three monolayers as $0.4 \mathrm{mC} \mathrm{cm}{ }^{-2}$ $\cong 1$ monolayer of $\mathrm{ZnO}$.

The anodic current plateau is related to the dealloying of $\beta$-brass as in this potential range soluble $\mathrm{Zn}$, probably $\mathrm{ZnCl}_{4}{ }^{2-}$, and no soluble $\mathrm{Cu}$ species are found. Hence, according to these results the anodic current plateau should be mainly related to dealloying involving the preferential electrodissolution of $\mathrm{Zn}$ through a thin, and presumably incomplete, $\mathrm{ZnO} \cdot \mathrm{HH}_{2} \mathrm{O}$ layer. The fact that the current plateau is independent of $\omega$ allows us to discard a dealloying kinetics controlled by the diffusion of $\mathrm{ZnCl}_{4}{ }^{2-}$ ions from the metal surface outward.

On the other hand, the small and reversible $\mathrm{A}(\mathrm{II}) /$ $\mathrm{C}$ (II) conjugated pair of peaks (Figure $2 \mathrm{a}-\mathrm{c}$ ) is assigned to the electroadsorption of $\mathrm{Cl}^{-}$on the $\mathrm{Cu}$-rich areas. ${ }^{19}$ Finally, the marked increase in current related to peak A(III) can be attributed to the electrodissolution of both $\mathrm{Cu}$ and $\mathrm{Zn}$ as $\mathrm{ZnCl}_{4}{ }^{2-}$ and $\mathrm{CuCl}_{2}{ }^{-}$complexes, respectively, and $\mathrm{CuCl}$ electroformation, ${ }^{20}$ whereas peak C(III) can be assigned to the electroreduction of soluble $\mathrm{Cu}$ species ${ }^{20}$ produced in the preceding anodic potential scan.

4.2. The Probable Reaction Mechanism of $\beta$-Brass Dealloying. Dealloying of $\beta$-brass can be described as a localized corrosion process at the atomic level which seemingly occurs at a stirring-independent and slightlydependent potential rate. These kinetic characteristics would imply a rate-controlling step involving either a diffusion of $\mathrm{Zn}$ atoms from bulk alloy to the corroding surface or a surface diffusion of the remaining $\mathrm{Cu}$ atoms. The first possibility corresponds to a solid state diffusion mechanism ${ }^{9}$ which at a constant $E_{\mathrm{s}}$ predicts a $j \propto t^{-1 / 2}$ relationship for $t \rightarrow 0$, rather than the $j \propto t^{-0.75}$ dependence experimentally observed. Therefore, the first explanation should be, in principle, ruled out. In fact, the $j \propto t^{-0.75}$ decay law can be related to a dealloying mechanism involving a surface diffusion process with presumably $\mathrm{Cu}$ atoms as rate controlling. ${ }^{13}$

Further arguments in favor of a dominant contribution of $\mathrm{Cu}$ atom surface mobility to the kinetics of $\beta$-brass dealloying can be derived from the topographic analysis 

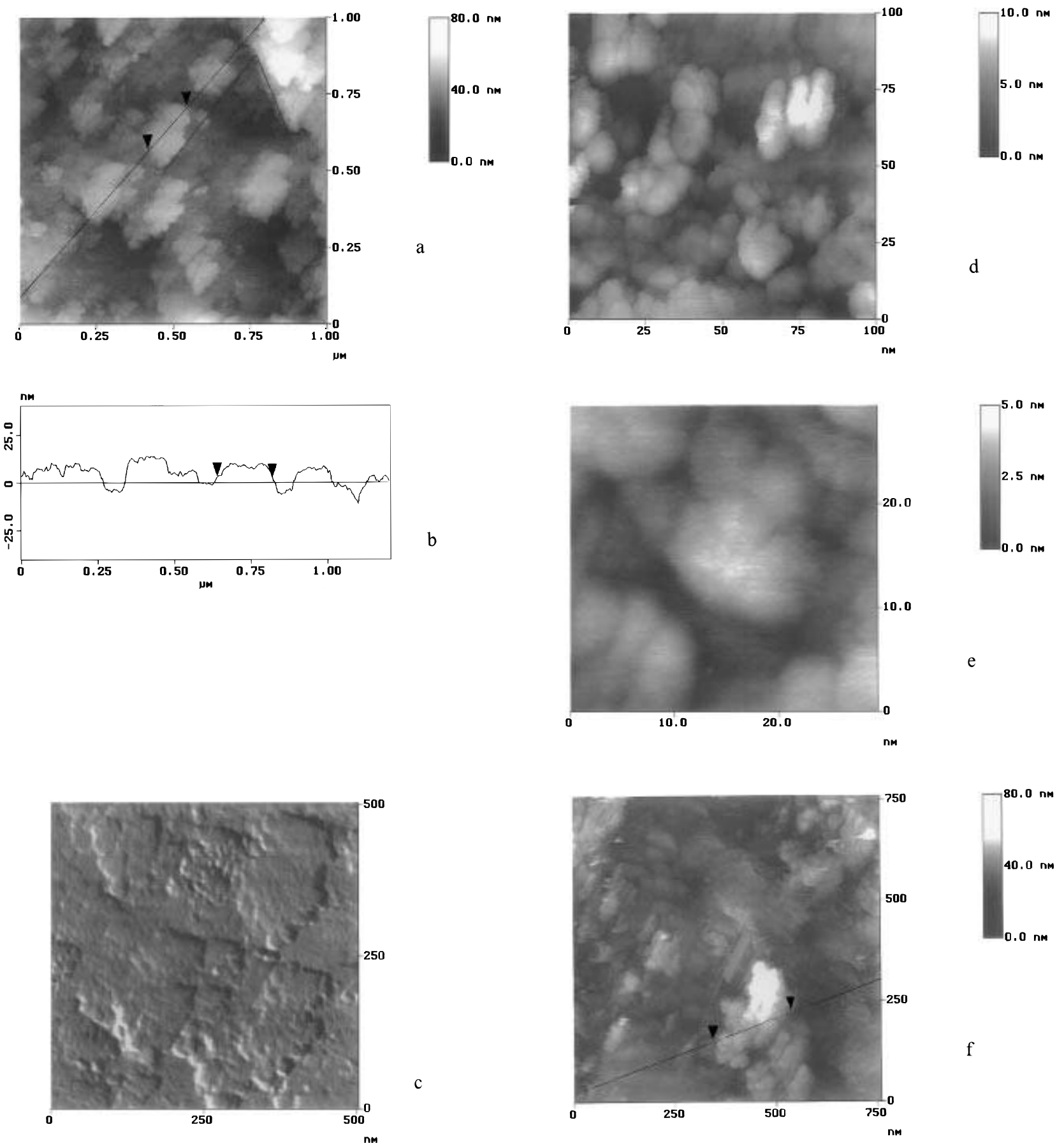

c

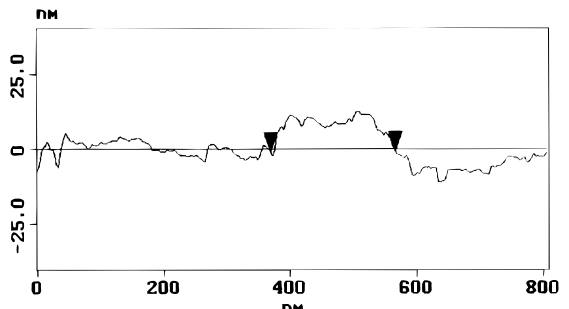

$\mathrm{d}$

b

Figure 3. STM images of a $\beta$-brass specimen after polarization at $E_{\mathrm{s}}=-0.625 \mathrm{~V}$ in aqueous $0.5 \mathrm{M} \mathrm{NaCl}$ for the time $t, 25^{\circ} \mathrm{C}$, $\omega=0 \mathrm{rpm}$ : (a) a $1 \times 1 \mu \mathrm{m}^{2}$ STM image, $t=24 \mathrm{~h}$, the marked angle is $60^{\circ}$; (b) cross section at the line marked in Figure $3 a$, island profiles are resolved, a $190 \mathrm{~nm}$ island size is marked by arrows; (c) a $500 \times 500 \mathrm{~nm}^{2}$ STM image (slope mode), $t=24 \mathrm{~h}$, island borders can be distinguished; (d) a $100 \times 100 \mathrm{~nm}^{2} 3 \mathrm{D}$ STM image, $t=24 \mathrm{~h}$; (e) a $30 \times 30 \mathrm{~nm}^{2} 3 \mathrm{D}$ STM image, $t=24 \mathrm{~h}$; (f) a 750 $\times 750 \mathrm{~nm}^{2}$ STM image, $t=48 \mathrm{~h}$; (g) cross section at the line marked in Figure $3 \mathrm{f}$, the size of the $200 \mathrm{~nm}$ remaining island is marked by arrows.

of the corroding interface itself. Experimental data show that as $E_{\mathrm{s}}$ is moved to the potential range of peak A(II), the surface coverage by $\mathrm{Cl}^{-}$increases, and accordingly, smoother terraces are formed. Under these conditions, however, the value of $\xi_{\mathrm{stm}}$ increases due to the faceting produced as $E_{\mathrm{s}}$ is shifted positively (Figure 5). 

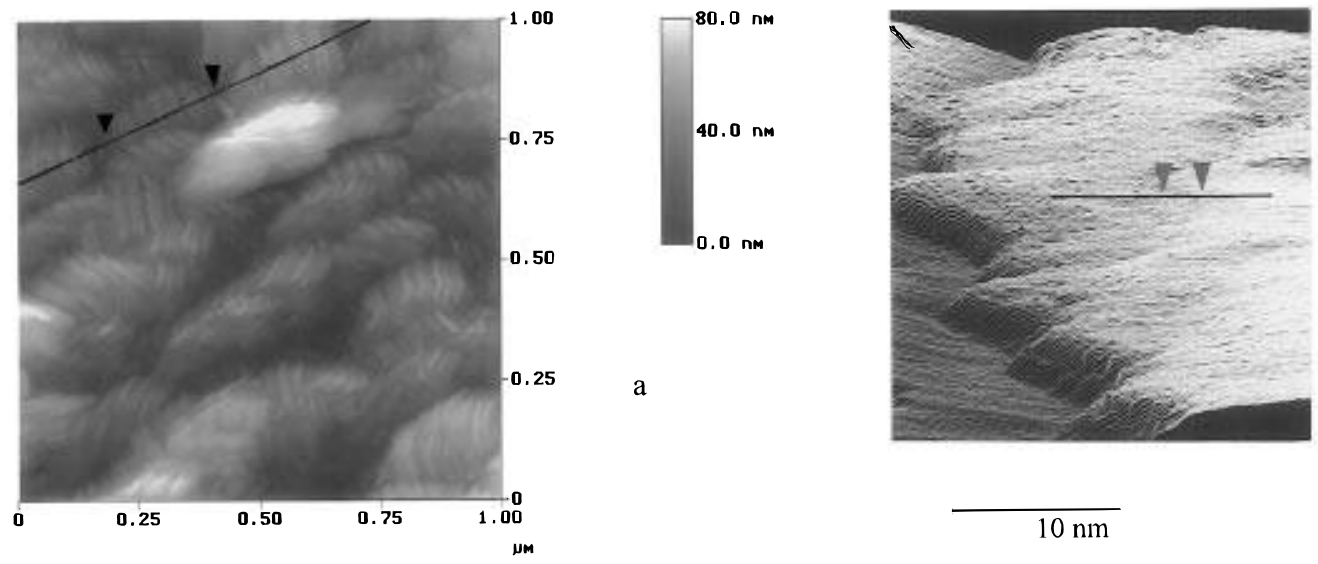

d
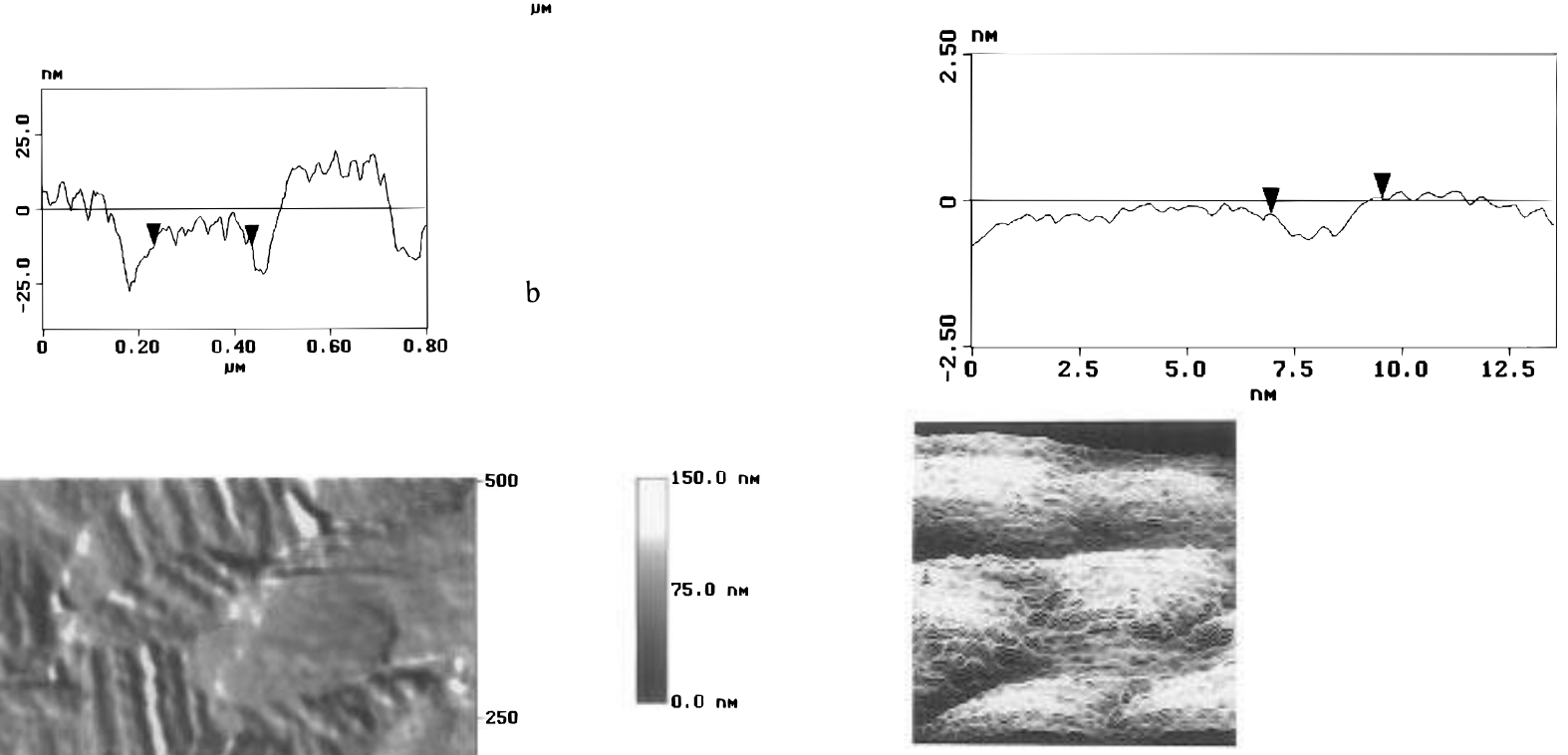

e
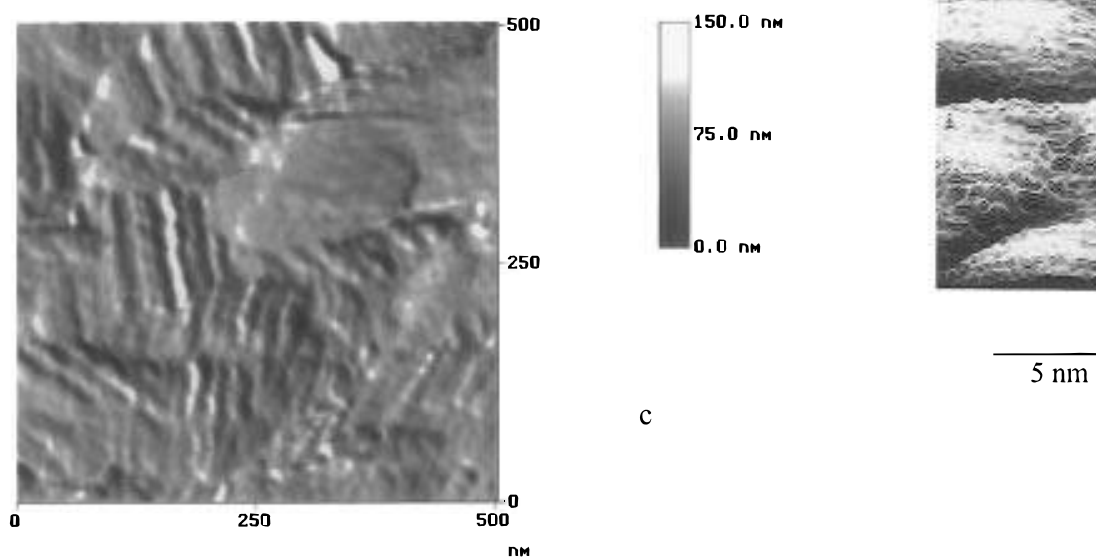

f

$\mathrm{c}$

Figure 4. STM images of a $\beta$-brass specimen after polarization at $E_{\mathrm{s}}=-0.450 \mathrm{~V}$ in aqueous $0.5 \mathrm{M} \mathrm{NaCl}$ for the time $t=24 \mathrm{~h}$, $25{ }^{\circ} \mathrm{C}, \omega=0 \mathrm{rpm}$ : (a) a $1 \times 1 \mu \mathrm{m}^{2}$ STM image; (b) cross section taken as indicated by the line marked in Figure 4a, island profiles are resolved, a $200 \mathrm{~nm}$ island size is marked by arrows; (c) a $500 \times 500 \mathrm{~nm}^{2}$ STM image (slope mode), faceted islands can be distinguished; (d) a $25 \times 25 \mathrm{~nm}^{2}$ 3D STM image, height difference $0 \leq z \leq 3 \mathrm{~nm}$; (e) cross section taken as indicated by the line marked in Figure 4d, atomically smooth terraces and monoatomic height steps are shown, arrows indicate a 0.27 nm vertical distance; (f) a $15 \times 15 \mathrm{~nm}^{2}$ 3D STM image, height difference $0 \leq z \leq 2 \mathrm{~nm}$.

The roughness evolution of the corroding interface can be analyzed in terms of the dynamic scaling theory. ${ }^{15}$ This theory predicts that $\xi(L,\langle h\rangle)$, the root mean square roughness for a sample formed by $N$ particles, length $L$, and average thickness or height $\langle h\rangle$, scales as

$$
\xi(L,\langle h\rangle) \propto L^{\alpha} \mathrm{f}(x)
$$

where $\xi(L,\langle h\rangle)$ is defined by

$$
\xi(L,\langle h\rangle)=\left[1 / N \sum\left[h\left(x_{\mathrm{i}}\right)-\langle h\rangle\right]^{2}\right]^{1 / 2}
$$

$h\left(x_{\mathrm{i}}\right)$ is the deposit height measured along the $x$-direction at the point $x_{\mathrm{i}}$, and $x=\langle h\rangle / L^{\alpha / \beta}$. Furthermore, $\mathrm{f}(x)$ has the following properties: $\mathrm{f}(x)=$ const for $x \Rightarrow \infty$, and $\mathrm{f}(x)=x^{\beta}$ for $x \Rightarrow 0$. Therefore, for $\langle h\rangle \Rightarrow 0$ eq 1 becomes

$$
\xi(\langle h\rangle) \propto\langle h\rangle^{\beta}
$$

whereas for $\langle h\rangle \Rightarrow \infty, \xi(L,\langle h\rangle)$ reaches a steady state, and eq 1 becomes

$$
\xi(L) \propto L^{\alpha}
$$

where $\beta$ and $\alpha$ are the dynamic and static growth exponents, respectively.

The value of $\alpha$ is related to $D_{\mathrm{s}}$, the local fractal dimension, of the self-affine surface through the relationship

$$
D_{\mathrm{s}}=d-\alpha
$$

where $d$ is the space dimension of the corroding interface. Accordingly, the value of $\alpha$ contains valuable information about the corroding surface disorder and the mechanism of the rough interface growth. ${ }^{15}$ To evaluate $\alpha$, it is necessary that the steady state roughness regime be attained. Experimental data (Figure 5) indicate that this roughness is attained for $\beta$-brass polarized for $24 \mathrm{~h}$ at either $E_{\mathrm{s}}=-0.625 \mathrm{~V}$ or $E_{\mathrm{s}}=-0.45 \mathrm{~V}$. Then, the value 


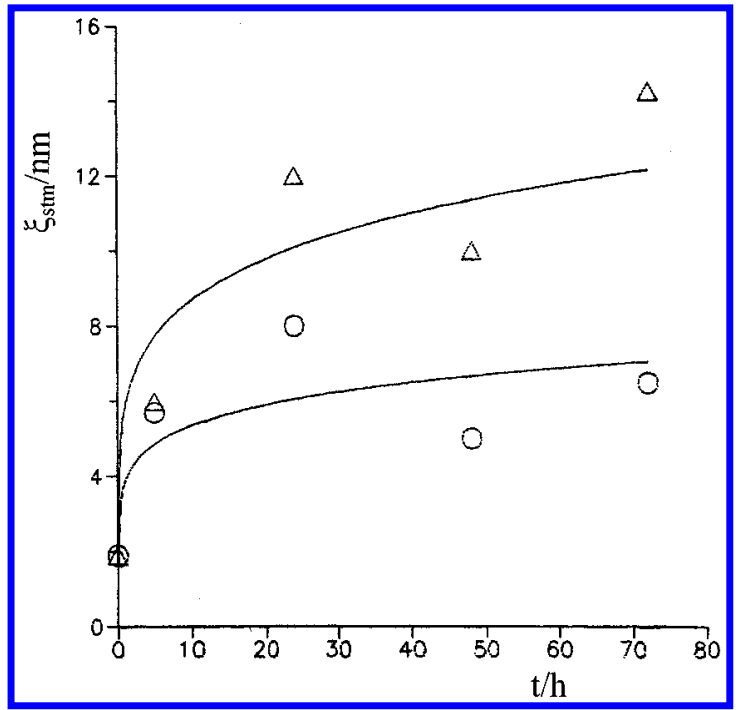

Figure 5. $\xi_{\text {stm }}$ vs $t$ plots derived from $1 \times 1 \mu \mathrm{m}^{2}$ STM images of $\beta$-brass after polarization in aqueous $0.5 \mathrm{NaCl}$ at $E_{\mathrm{s}}=-0.625$ $\mathrm{V}(\mathrm{O})$ and $E_{\mathrm{s}}=-0.45 \mathrm{~V}(\triangle), 25{ }^{\circ} \mathrm{C}$.

of $\alpha$ can be obtained from the analysis of STM images by using the single image dynamic scaling method. ${ }^{18,23}$

The single image dynamic scaling derives the value of $\alpha$ from the equation

$$
\xi_{\mathrm{stm}}\left(L_{\mathrm{s}},\langle h\rangle\right) \propto L_{\mathrm{s}}^{\alpha}
$$

by plotting $\log \xi_{\mathrm{stm}}$ vs $\log L_{\mathrm{s}}$, where $L_{\mathrm{s}}$ is the length of a segment of the STM scan of size $S$ measured in the $x$-direction. For each scan, 486 pairs of data points $\left(L_{\mathrm{s}}\right.$, $\left.\xi_{\text {stm }}\right)$ have been obtained, $L_{\mathrm{s}}$ being varied from $S / 128$ to $0.96 S$. Finally, for each $L_{\mathrm{s}}$, the corresponding $\xi_{\mathrm{stm}}$ represents the average value resulting from 512 scans of the same image.

The $\log \xi_{\text {stm }}$ vs $\log L_{\mathrm{s}}$ plots (Figure 6a) resulting from STM images of $\beta$-brass surfaces polarized for $24 \mathrm{~h}$ at $E_{\mathrm{s}}$ $=-0.65 \mathrm{~V}$ approach a straight line with the slope of 0.67 \pm 0.05 covering more than 1 decade in $L_{\mathrm{s}}$. On the other hand, the $\log \xi_{\mathrm{stm}}$ vs $\log L_{\mathrm{s}}$ plots (Figure $6 \mathrm{~b}$ ) resulting from STM images of $\beta$-brass polarized for $24 \mathrm{~h}$ at $E_{\mathrm{s}}=-0.45$ $\mathrm{V}$ also result in straight lines with the slope $\alpha=0.80 \pm$ 0.07 for more than 2 decades of magnitude in $L_{\mathrm{s}}$ and a saturation region for $L_{\mathrm{s}}>200 \mathrm{~nm}$. This value of $L_{\mathrm{s}}$ is close to the average size of islands observed by STM imaging. Furthermore, straight line plots presented in Figure 6 are displaced upward, i.e., to larger $\xi_{\text {stm }}$ values, as $E_{\mathrm{s}}$ is displaced positively.

It should be noted that for computer-simulated fractals, data covering 4 to 5 orders of magnitude are required for logarithmic fitting. However, for experimental systems this goal is less ambitious due to the existence of inner and outer cutoffs. ${ }^{15}$ This means that the fractal character of a real system is restricted to well-defined limits. For our system the inner cutoff should be related to the size of atoms and the outer cutoff to the size the islands. Obviously, in $1 \times 1 \mu \mathrm{m}^{2}$ STM images used for fractal characterization only the outer cutoff can be clearly determined. Accordingly, the $\log \xi_{\mathrm{stm}}$ vs $\log L_{\mathrm{s}}$ linear plots derived from experimental data covering approximately at least 1 order of magnitude are considered acceptable.

Average values of $\alpha$ resulting from 15 different STM images taken in the range $25 \mathrm{~nm}<L_{\mathrm{s}}<1000 \mathrm{~nm}$, for $\beta$-brass surfaces polarized at either $E_{\mathrm{s}}=-0.45 \mathrm{~V}$ or $E_{\mathrm{s}}=$ $-0.65 \mathrm{~V}$, are $\langle\alpha\rangle=0.80 \pm 0.07$ and $\langle\alpha\rangle=0.70 \pm 0.05$,

(23) Vázquez, L.; Salvarezza, R. C.; Herrasti, P.; Ocón, P.; Vara, J. M.; Arvia, A. J. Chaos, Solitons and Fractals 1995, 6, 569.

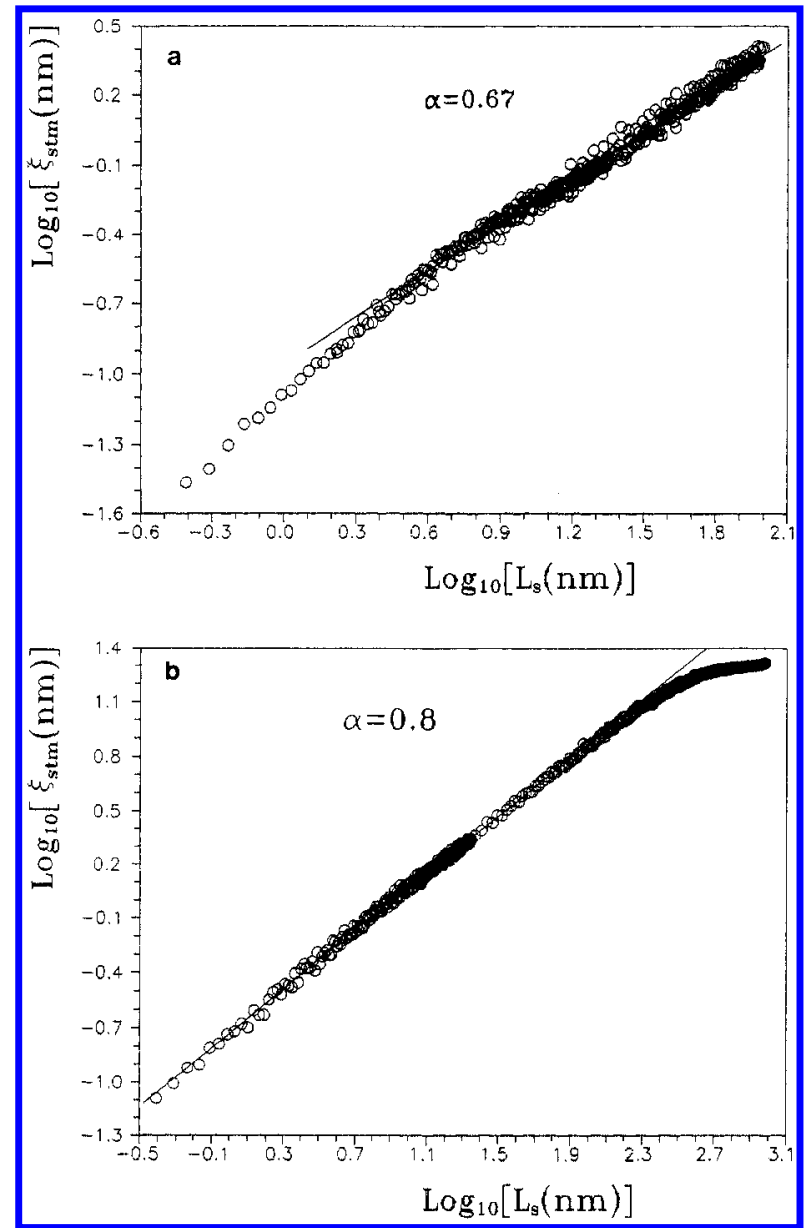

Figure 6. $\log \xi_{\text {stm }}$ vs $\log L_{\mathrm{s}}$ plot resulting from STM images of $\beta$-brass polarized in aqueous $0.5 \mathrm{M} \mathrm{NaCl}$ at $E_{\mathrm{s}}=-0.625 \mathrm{~V}$ (a) and $E_{\mathrm{s}}=-0.45 \mathrm{~V}$ (b), $25^{\circ} \mathrm{C}$. Data correspond to the steady state roughness regime at the dissolving interface $(t=24 \mathrm{~h}$, see Figure 5).

respectively. Similar values of $\alpha$ were obtained for $\beta$-brass specimens kept at either $E_{\mathrm{s}}=-0.625 \mathrm{~V}$ or $E_{\mathrm{s}}=-0.45 \mathrm{~V}$ for $72 \mathrm{~h}$. The increase in the value of $\alpha$ from 0.70 to 0.80 indicates the dominant influence of faceting on the topography of the corroding interface as $E_{\mathrm{s}}$ is increased positively. It should be noted that $\alpha=1$ is expected for an ideal stepped surface with smooth terraces. ${ }^{24}$

The value of $\alpha$ provides information about the probable interface growth mechanism. Several growth models, such as the Eden, ${ }^{25}$ ballistic deposition, ${ }^{26}$ and restricted solid-on-solid models, ${ }^{27}$ have been proposed to explain nonequilibrium interface growth processes. These models can be successfully described by the Kardar, Parisi, and Zhang motion equation ${ }^{28}$ which leads to $\alpha=0.4$ in $3 \mathrm{D}$ space. Alternate models in 3D space incorporating surface diffusion yield either $\alpha=1.0^{29,30}$ or $\alpha=0.66$. $^{31}$ Despite the fact that these models are related to the development of a rough interface by aggregation rather than removal

(24) Salvarezza, R. C.; Arvia, A. J. Modern Aspects of Electrochemistry, in press.

(25) Eden, M. Proceeding of the 4th Berkeley Symposium on Mathematical Statics and Probability, Neyman, F., Ed.; University of California Press: Berkeley, 1961; Vol. 4

(26) Meakin, P.; Ramanlal, P.; Sander, L. M.; Ball, R. C. Phys. Rev. A 1986, 34, 509 .

(27) Gilmer, G. H.; Bennema, P. J. Appl. Phys. 1992, 43, 1347.

(28) Kardar, M.; Parisi, G.; Zhang, Y. C. Phys. Rev. Lett. 1986, 56, 889 .

(29) Wolf, D.; Villain, J. Europhys. Lett. 1990, 13, 389. Villain, J. J. Phys. I 1992, 1, 19.

(30) Siegert, M.; Plischke, M. Phys. Rev. Lett. 1994, 73, 1517.

(31) Lai, Z. W.; Das Sarma, S. Phys. Rev. Lett. 1991, 66, 2348. 
of material, it is clear that the corroding $\beta$-brass surface can be considered as a self-affine fractal resulting from vacancy aggregation. The surface mobility of the remaining $\mathrm{Cu}$ atoms results in the coalescence of vacancies and surface clustering leading to the characteristic voidcluster rough topography.

The role of surface mobility in determining the topography of the corroding interface is supported by the experimental values of $\alpha$ which are between $\alpha=1.0^{29,30}$ and $\alpha=0.66^{31}$ predicted for the interface growth models with surface diffusion.

Therefore, these models appear to be adequate to describe the rough $\beta$-brass surface topography developed in the corrosion process in aqueous NaCl-containing solution at room temperature.

The preceding mechanistic conclusion is not surprising due to the high surface mobility of $\mathrm{Cu}$ in vacuum, air, and liquids at room temperature,$^{32}$ especially in contact with $\mathrm{Cl}^{-}$in the environment. ${ }^{33}$ The slight increase in $\beta$-brass electrodissolution with $E_{\mathrm{s}}$ should be related to an enhanced surface mobility of $\mathrm{Cu}$ atoms produced as the $\mathrm{Cl}^{-}$surface coverage increases. ${ }^{34}$

Finally, it should be noted that the bulk diffusion of $\mathrm{Zn}$ becoming a rate-determining step in the kinetics of $\beta$-brass electrodissolution in aqueous environments would have led to a branched DLA-like interface ${ }^{35}$ rather than the

(32) Behm, R. J. Scanning Tunneling Microscopy and Related Methods; Behm, R. J., García, N., Röhrer, H., Eds.; Kluwer Academic Publishers: Boston, MA, 1989; p 173. faceted island-like topography observed by STM imaging. Therefore, this observation, and the $j$ vs $t^{-0.75}$ current decay law support a surface diffusion controlling mechanism for the kinetics of $\beta$-brass dealloying in aqueous $\mathrm{NaCl}$ containing solution.

\section{Conclusions}

For the first time it has been demonstrated that a corroded surface of an alloy can be described as a selfaffine fractal obeying the relationship $\xi \propto L^{\alpha}$ with $\alpha$ values compatible with a vacancy aggregation process with surface diffusion contributions. Therefore, the analysis of the rough topography under the steady state regime provides a new way to determine the mechanism of corrosion processes.

Acknowledgment. The authors thank UNELCO S.A. (Unión Eléctrica de Canarias S.A.), Dirección General de Investigación Científica y Técnica (DGICYT) (Spain), and Consejo Nacional de Investigaciones Científicas y Técnicas (CONICET) (Argentina) for their financial support of this work.

\section{LA950409F}

(33) Bonzel, H. P. Surface Physics of Materials; Blakely, J. M., Ed.; Academic Press: New York, 1975; p 280.

(34) García, P.; Goméz, M.; Salvarezza, R. C.; Arvia, A. J. J. Electroanal. Chem. 1993, 347, 237.

(35) Hernández-Creus, A.; Salvarezza, R. C.; Arvia, A. J. In preparation. 